\title{
The Research For Designing College MOOC Standard Based On Cognitive Learning Theory
}

\author{
YangZhiShang, a \\ ${ }^{1}$ Changsha Medical University, Changsha, Hunan,413000 China \\ a284204813@qq.com
}

Keywords: MOOC, designing standard, college teacher

\begin{abstract}
After entering 21 century, education has been influenced by the informatization and globalization. The popularization of Internet and computer technology in education shows possibility in reforming traditional teaching modes. English MOOC is generated, and its teaching modes are combined the advanced Internet information technology with innovative teaching theory, which overturn traditional teaching modes and receive wide attention. This paper is going to studying college MOOC standard that based on cognitive learning theory.
\end{abstract}

\section{Introduction}

In recent years, the individual study is popular in college education and it accelerates the multiple development in teaching methods and learning methods. "teaching" and "learning" have become more convenient with high interactivity. Particularly, "learning" is going to be more compact, fragmentary and convenient. MOOC is a new mode, which has authentic experience, prominent topic, flexible method, high interactivity and is easy to communicate and operate. It has a bright future in the classes.

\section{The characteristics of college English MOOC platform that based on cognitive}

\section{learning theory}

According to the connotation of MOOC, though different people have different opinions, the mainly features of MOOC are as follows:

Chart1: the characteristics of MOOC

\begin{tabular}{|c|c|c|c|c|}
\hline $\begin{array}{c}\text { Characteristics } \\
\text { of MOOC }\end{array}$ & less content & $\begin{array}{l}\text { Shorter teaching } \\
\text { time }\end{array}$ & $\begin{array}{l}\text { Specific subject } \\
\text { and target }\end{array}$ & $\begin{array}{c}\text { Micro-video is the } \\
\text { mainly carrier }\end{array}$ \\
\hline $\begin{array}{c}\text { Specific } \\
\text { description }\end{array}$ & $\begin{array}{l}\text { From the meaning of } \\
\text { MOOC, it aims at an } \\
\text { individual knowledge } \\
\text { point or a teaching } \\
\text { section. The teaching } \\
\text { activity is relatively } \\
\text { narrow } \\
\text { concentrates on the } \\
\text { individual knowledge } \\
\text { point. }\end{array}$ & $\begin{array}{l}\text { The most important } \\
\text { feature is micro, } \\
\text { which shows in } \\
\text { teaching time. The } \\
\text { time of a MOOC is } \\
\text { about } 10 \text { minutes. }\end{array}$ & $\begin{array}{l}\text { The selection of its } \\
\text { knowledge points } \\
\text { is single, and each } \\
\text { lesson has each } \\
\text { topic with high } \\
\text { specification. }\end{array}$ & $\begin{array}{l}\text { Each MOOC has each } \\
\text { micro-video, and the } \\
\text { video can indicate } \\
\text { teaching content. }\end{array}$ \\
\hline
\end{tabular}


Chart 2: The differences between MOOC and traditional lessons

\begin{tabular}{|c|c|c|}
\hline Items & MOOC & Traditional lessons \\
\hline Time & Within 10 minutes & 45minutes, or 40 minutes(sometimes) \\
\hline Content & Single knowledge points & $\begin{array}{c}\text { According to the textbooks, the body is } \\
\text { the content of a lesson. }\end{array}$ \\
\hline Goal & To master the single knowledge points & To master the content of a lesson \\
\hline Carrier & Micro-video & Teacher and student have to face to face \\
\hline Site & Anywhere & classroom \\
\hline Repetition & Can be repeated & Systematic study \\
\hline Application method & Fragmentary study & \\
\hline Presentation method & $\begin{array}{c}\text { Through media, animation and special } \\
\text { effect processing }\end{array}$ \\
\hline
\end{tabular}

The cognitive load can be divided into extraneous cognitive load, intrinsic cognitive load and germane cognitive load. It can be showed in the following diagram. Learners who establish proper schema need more cognitive resources, so that intrinsic cognitive appeared. The germane cognitive load relates to schema automatic processing and schema establishment. For example, learners can induct when they learn a kind of skill. In this processing, cognitive load can be produced. It can optimize learners’ cognitive structure and reduce working memory load.
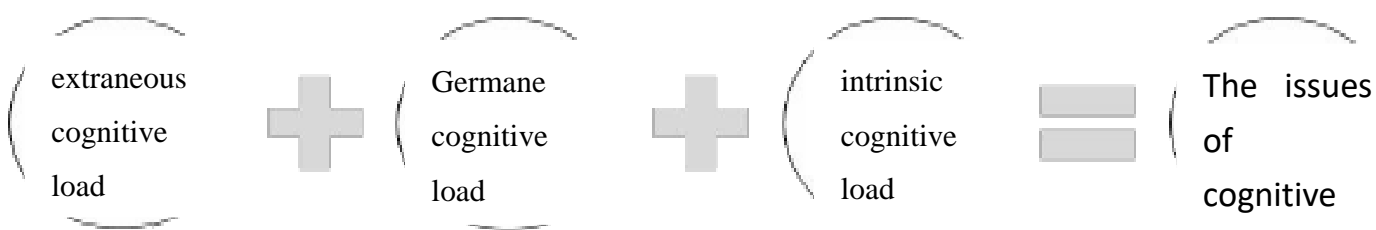

Diagram1: the relationship among three kinds of cognitive load

According to the analysis of diagram 1, since the extraneous cognitive load is useless whereas the germane cognitive load is useful, thus we can reduce the extraneous cognitive load in teaching processing to increase germane cognitive load and improve learning efficiency. According to the cognitive load theory, the design of MOOC should pay attention to the following aspects: firstly, it must be easily understood and remembered, as well as exquisite content. It should focus on the relevance of teaching content, which makes an easier teaching schema.

From the dimension of cognitive processing, the specific verb check list contributes to subject analysis and classification in the real teaching activity.

Chart 3 verb check list

\begin{tabular}{|c|c|}
\hline Cognitive processing & Relevant verbs \\
\hline Memory & nominate, describe, relate, find, list, write, distinguish \\
\hline Comprehension & explain,compare, repeat, forecast, reverse, summarize \\
\hline Application & display, complete, use, classify, check, illustrate, solve \\
\hline Analysis & explain, compare, contrast, check, recognize, research, classify \\
\hline Evaluation & arbitrate, rank, select, establish, conform, evaluate, optimize \\
\hline Creation & create, innovate, plan, organize, establish, design, imagine \\
\hline
\end{tabular}

The analysis of designing college English MOOC standard that based on cognitive learning theory

1. In designing MOOC, some problems should be focused:

--What is its position and function in the teaching processing? 
--Is teaching scene or fragmentary editing?

--Is visible textbook-based procedure?

--Whether it can show a teacher's teaching process?

--How to indicate the interactivity between teachers and students, or between students and students?

--What is the processing environment, processing modes and platform?

--What is the teaching modes?

--How to evaluate teaching efficiency for teachers and students?

--How to resolve and integrate teaching explaining, operating and feedback?

2. The steps of designing college English MOOC

\section{Topic selection} teaching expression

teaching content

Diagram 2 the steps of designing college English MOOC

It is a Wechat-based teaching mode, which has shorter teaching time, easier teaching design and independent study. In the teaching processing, it plays an important role and promotes teaching modes. The features of Internet make it a perfect interaction with amount of knowledge. It can reduce teaching time as well as improve students' attention.

(1) Topic selection

The Wechat-based MOOC is not confined to the traditional teaching method, and teaches students in accordance of their aptitude. It can achieve teaching goals.

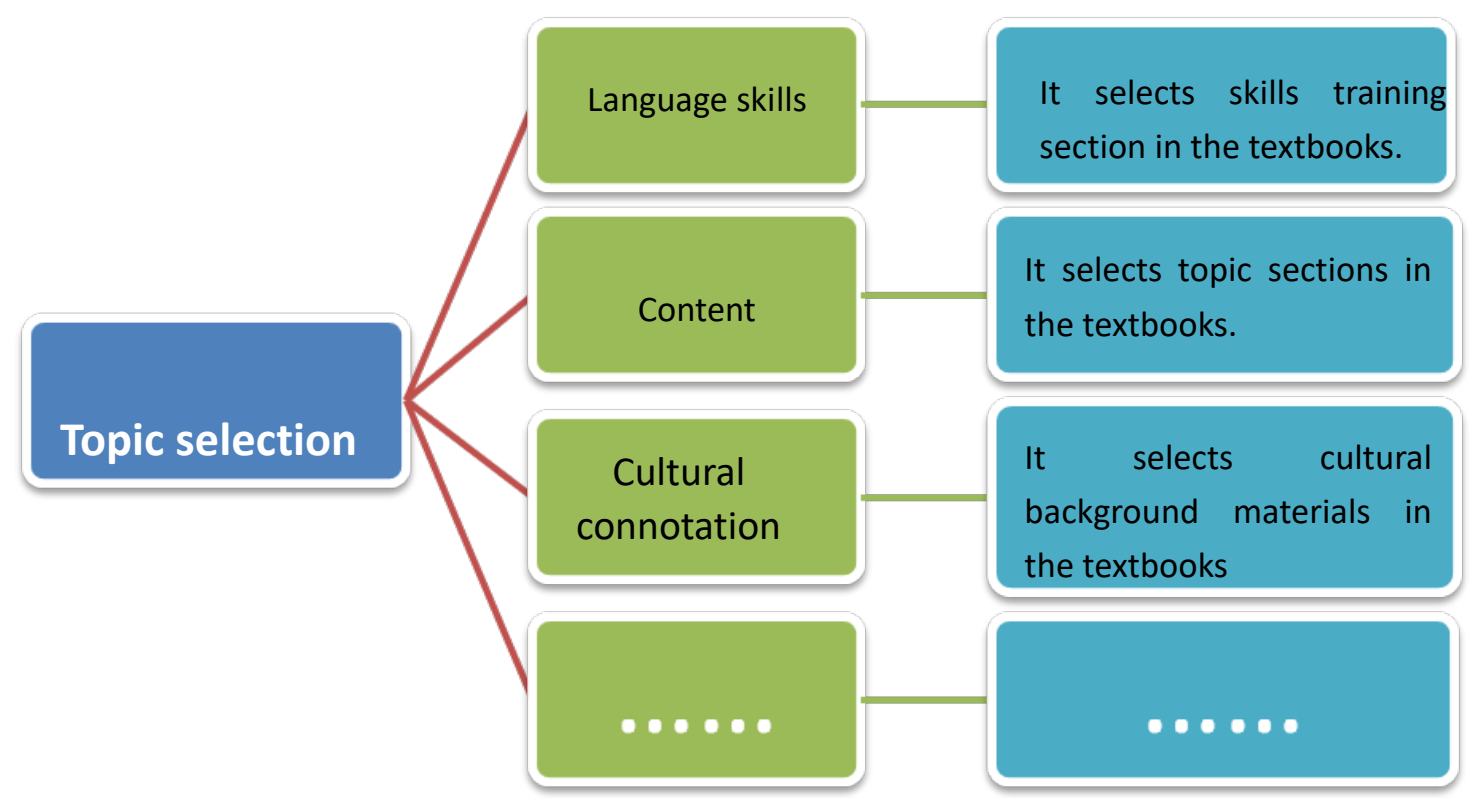

(2) Teaching content

The subject of the Wechat-based MOOC is to achieve teaching goals in the course arrangement. The proper effect that students receive is based on the goals of this platform. The teaching goals can be divided into knowledge goals, capacity goals and emotion goals.

(3) Teaching strategy

The college MOOC is a teaching design that aims at some knowledge points. It has small pointcut, specific purpose, wide selection and concentrated content. On the one hand, teachers can select multiple content from college English; on the other hand, students can choose relative content to study according to their actual situation and demands. When designing the MOOC, teachers adequately understand English foundation of students. They emphasize mistakes that students are inclined to make, in order that students can optimize the actual effect in independent study. 
Chart 5

\begin{tabular}{|l|l|c|}
\hline Unit & Content & Time(minutes) \\
\hline Unit 1 & Passive Voice in English-Chinese Translation & 10 \\
\hline Unit 2 & Numbers in English-Chinese Translation & 9 \\
\hline Unit 3 & Omission in English-Chinese Translation & 9 \\
\hline Unit 4 & Restructuring in English-Chinese Translation & 10 \\
\hline Unit 5 & Long Sentences in English-Chinese Translation & 10 \\
\hline
\end{tabular}

(4) Teaching expression

The phase of study includes preparation before class and teaching in the class. Firstly, during the preparation, MOOC is the micro teaching material that is selected and recorded by teachers. Its content focus on the knowledge points and new information. At the same time, teachers should have fluent and refined words to emphasize key points and difficulties in the video. Although short, it still have the completed teaching procedure. Secondly, in teaching and learning section, students should watch the video, answer questions and positively take part in the class discussion. Teachers make the most of students' optimum attention to avoid absent-minded. On the other hand, teachers should answer questions for students. In the class, students are divided into groups to discuss difficulties and key points, then teachers will record a video again to resolve these problems. After mastering these knowledge points, students have to finish the homework that released on the platform. Discussion and online homework can help students deeply comprehend knowledge points and apply them to the actual situation, which improve study efficiency.

(5) Teaching feedback

The features of MOOC is to flexibly arrange studying time and sites. Teachers should promptly give feedback to students about their performance. Students will be evaluated through question resolution, micro-text and learning report. Besides, teachers should supplement and explain the knowledge points that students cannot master, as well as amend and evaluate homework.

3. Examples for designing college English MOOC

\section{Four Ps}

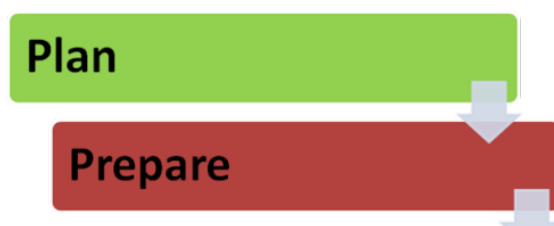

Predict

Produce

diagram 4 designing steps 

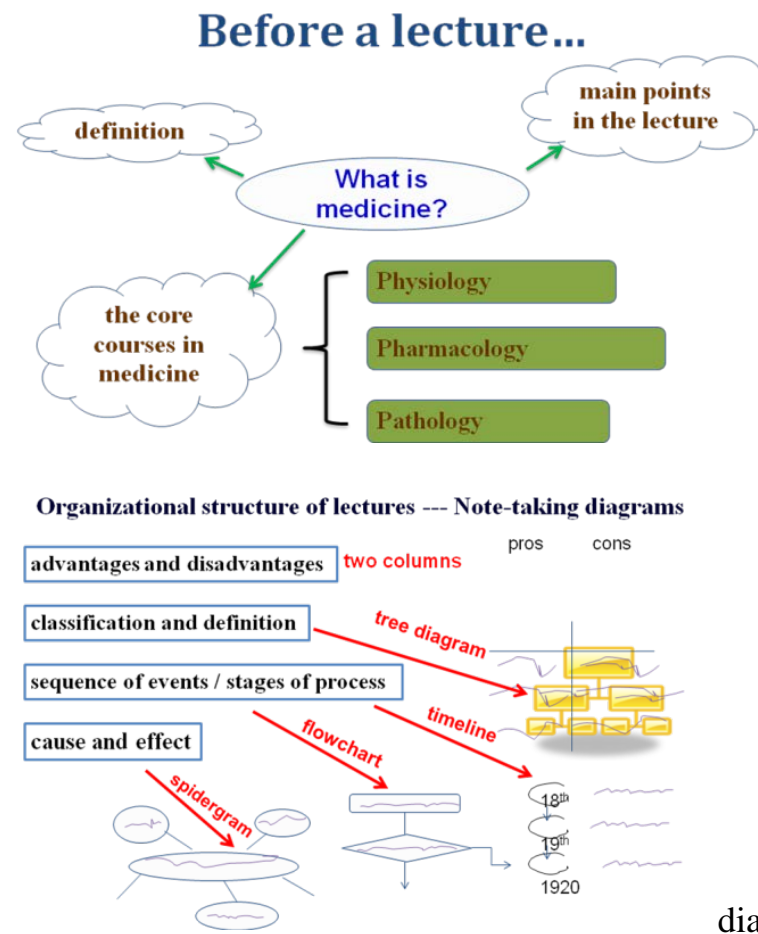

diagram 6 designing idea

\section{Choosing diagrams}

Listen to three lecture introductions. After listening, please choose a possible note-diagram for each lecture.

Lecture 1

Lecture 2

Lecture 3

diagram 7 content planning

\section{Conclusion}

The college MOOC is a teaching design that aims at some knowledge points. It has small pointcut, specific purpose, wide selection and concentrated content. On the one hand, teachers can select multiple content from college English; on the other hand, students can choose relative content to study according to their actual situation and demands. It optimizes the actual study efficiency in the MOOC.

\section{References}

[1]Chuanzhen, Xia. The Study Of CIP-based College English MOOC Mode [J]. Education Forum,2015,22:161-162.

[2] Yunxia, Zhong. The Analysis Of Designing College English Writing Procedure That Based On the Cognitive Load Theory [J]. Dezhou University Report[J]. ,2017,01:29-33.

[3]Jing, Zhu, Xiaojun,Su. The MOOC Establishment And Application Of Cognitive Language--Taking College English Trough Watching, Listening And Speaking as Example[J].CAFLT ,2015,05:21-25.

[4] Songmen, Shi. The Study Of College English MOOC System[J]. Jiangsu Open University Report,2014,03:37-41.

[5]Aimei, Ma. The multimodal Discourse Analysis Of College English MOOC Practice[J]. Hunan 
Technology University Report,2015,12:188-191. 